\section{Charcoal-induced pseudomelanosis ilei}

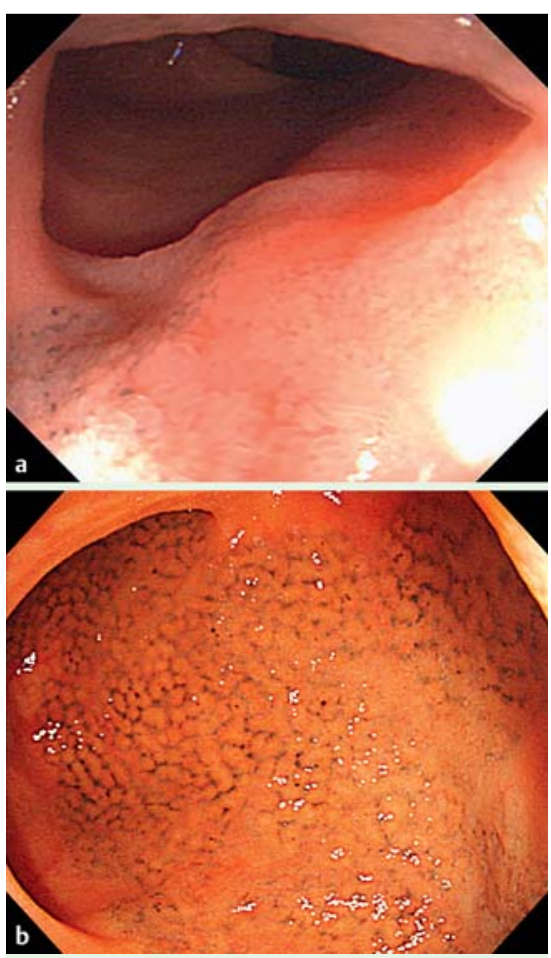

Fig. 1 Endoscopic view of the terminal ileum showing numerous areas of dark pigmentation during: a the initial colonoscopy; $\mathbf{b}$ the surveillance colonoscopy 5 year later.

A 32-year-old woman was referred to our outpatient department because of anal bleeding. She had been diagnosed with ulcerative proctitis about 1 year previously and had experienced intermittent anal bleeding during treatment at a local clinic. She had no significant medication history and in particular had not used laxatives or oral iron. The initial colonoscopy revealed numerous variable-sized areas of black

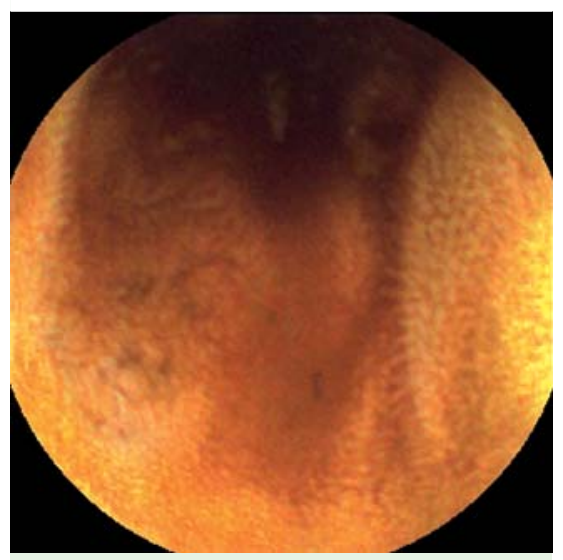

Fig. 2 Capsule endoscopy showing gray to black pigmented mucosa in the terminal ileum.

pigmentation in the mucosa of the terminal ileum ( $\bullet$ Fig. 1 a); however, the pigment was not detected in the colorectum. A capsule endoscopy also demonstrated the areas of pigmentation in the terminal ileal mucosa, although the remainder of the small bowel appeared normal (๑ Fig. 2).

Histological examination of biopsy specimens showed coarse black particles with irregular borders that were freely dispersed or focally aggregated in the lamina propria and submucosa ( $\bullet$ Fig. 3 ).

These areas of pigmentation were negative with Prussian blue and Fontana-Masson stains.

The patient's medication history was reviewed after the evaluation; it was revealed that she had taken two teaspoons of edible charcoal powder daily for 2 days to relieve abdominal pain before the initial colonoscopy. Following this test, she took

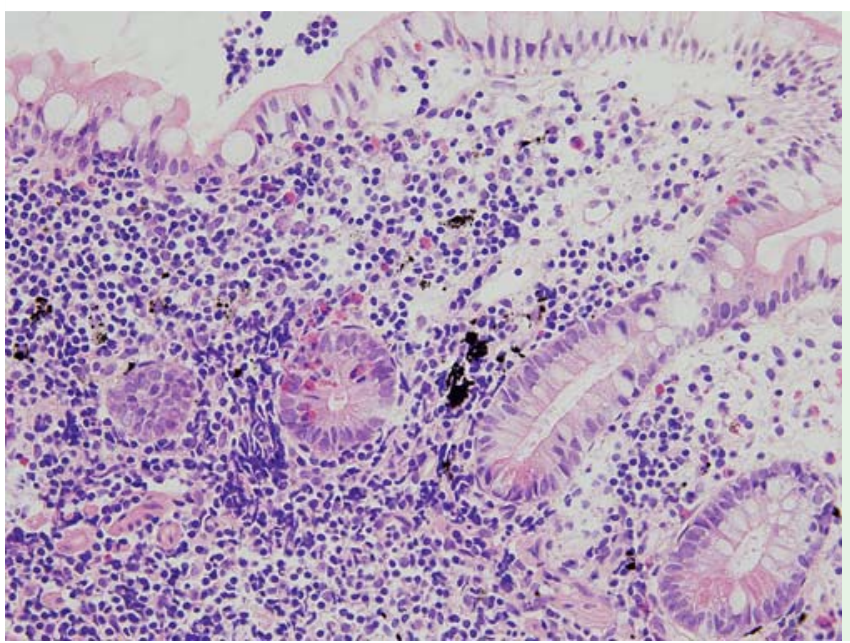

Fig. 3 Histological view of the terminal ileal mucosa showing brown to black pigment deposition in the lamina propria. no further charcoal powder, but a surveillance colonoscopy performed 5 years later showed that the black pigmented mucosa in the terminal ileum remained unchanged $(\bullet$ Fig. 1 b).

Pseudomelanosis ilei is rarely reported and in most of the case reports, iron deposition has been observed in the ileum [1]. Charcoal-induced pseudomelanosis ilei is extremely rare, with only two cases having been reported in the English literature $[2,3]$. In our patient, the ileal pigment was thought to result from charcoal ingestion because she had not taken laxatives, oral iron, or antihypertensive agents, and the pigments in the biopsy specimens were negative for iron and melanin stains. The consequences of charcoal pigmentation are unknown, although it is believed to be a benign condition, as appears to be the case in our patient. Endoscopists should consider charcoal ingestion as one of the possible causes of pseudomelanosis ilei when they observe black pigmentation in the terminal ileum.

\section{Endoscopy_UCTN_Code_CCL_1AC_2AH}

\section{Competing interests: None}

\section{S. Y. Kim, J. S. Koo, J. J. Hynun,}

S. W. Jung, R. S. Choung, H. J. Yim,

S. W. Lee, J. H. Choi

Division of Gastroenterology, Department of Internal Medicine, Korea University

College of Medicine, Seoul, Korea

\section{References}

1 Almeida N, Figueiredo P, Lopes $S$ et al. Small bowel pseudomelanosis and oral iron therapy. Dig Endosc 2009; 21: $128-130$

2 Lee TH, Lee SH, Park JH et al. Melanosis ilei associated with chronic ingestion of edible charcoal. Gastrointest Endosc 2008; 67: 1174 discussion 1175

$3 \mathrm{Kim} J \mathrm{H}$, Hwang JK, Choi WS et al. Pseudomelanosis ilei associated with ingestion of charcoal: case report and review of literature. Dig Endosc 2010; 22: 56-58

\section{Bibliography}

DOI $10.1055 / \mathrm{s}-0030-1257042$

Endoscopy 2011; 43: E380

(c) Georg Thieme Verlag KG Stuttgart · New York . ISSN 0013-726X

\footnotetext{
Corresponding author J. S. Koo, MD, PhD

Division of Gastroenterology Department of Internal Medicine Korea University Ansan Hospital 516, Gojandong, Danwongu Ansan 425-707

Korea

Fax: +82-31-4125582

jskoo@korea.ac.kr
} 